\title{
A FUNÇÃO POLÍTICA DE RELAÇÕES PÚBLICAS NA LEGITIMAÇÃO ORGANIZACIONAL
}

\author{
Fabiane Sgorla ${ }^{\mathrm{i}}$ \\ Patrícia Milano Pérsigo \\ Maria Ivete Trevisan Fossáiii
}

\begin{abstract}
RESUMO
Os diversos atores sociais, sejam eles individuais ou coletivos, buscam constantemente sua legitimação no meio social em que se inserem, através dos processos de visibilidade. Os processos de relações públicas, desenvolvidos por profissionais de Relações Públicas, possuem um papel fundamental na legitimação das diversas organizações. No cenário atual, em que as mídias assumem função primordial no que se refere a visibilidade, as atividades, principalmente da função política de relações públicas ampliam sua importância na legitimação das organizações, atuando a partir de práticas estratégicas em ambientes midiáticos. Sob esse raciocínio, este artigo busca discutir a relação entre visibilidade e legitimação das organizações, bem como o papel das relações públicas nessa relação.
\end{abstract}

PALAVRAS-CHAVE: Função política; legitimação; Relações Públicas;.

\section{RESUMEN}

Los distintos agentes sociales, sean individuales o colectivos, buscan constantemente su legitimation en el ambiente social donde si insertan. Los procesos de relaciones públicas, desarrollados por profesionales de Relaciones Públicas, tienen un papel fundamental en la legitimation de las organizaciones. En el contexto actual, donde los medias asumen la función primordial con respecto a visibilidad, las actividades, principalmente de la función política, de relaciones públicas amplían su importancia en el legitimation de las organizaciones, actuando de forma estratégica en espacios mediáticos. Bajo estas proposiciones, este artículo objetiva discutir la relación entre la visibilidad y la legitimation de las organizaciones, así como el papel de las relaciones públicas en esta relación.

PALABRAS CLAVE: Función política; legitimation; Relaciones Públicas;

\begin{abstract}
The various social actors, whether individual or collective, constantly seek their legitimacy in the social environment in which they operate, through the processes of visibility. The processes of public relations, developed by public relations professionals, have a key role in legitimizing the various organizations. In the current scenario, in which the media assume primary role with regard to visibility, the activities, especially the political function of public relations extend its importance in legitimizing organizations, working from strategic practices in media environments. Under this reasoning, this article discusses the relationship between visibility and legitimacy of organizations, as well as the role of public relations in this relationship.
\end{abstract}

KEYWORDS: political function; legitimacy; Public Relations. 


\section{Apresentação}

As organizações em geral possuem uma necessidade iminente de adquirir legitimidade no contexto em que elas se inserem. O processo de legitimação esclarece a ordem institucional e concede validade a seus significados, implica a existência de valores e sua transmissão a gerações futuras. Para se legitimar frente à esfera social os sistemas organizacionais contemporâneos se utilizam de várias estratégias de visibilidade tanto midiáticas quanto não midiáticas.

No cenário atual, em que a mídia passa a fazer parte mais intensamente das relações entre os indivíduos, os processos de legitimação, por sua vez, acabam também sofrendo alterações. É nesse momento que os profissionais de Relações Públicas assumem uma posição estratégica, ativa e determinante na busca pela validação social da organização a qual assessoram (FOSSÁ e KEGLER, 2008).

A partir deste raciocínio o presente artigo busca discutir o papel das relações públicas na busca pela legitimação das organizações. Este estudo está amparado na pesquisa bibliográfica. Conforme Marconi e Lakatos (2006), o aprofundamento bibliográfico é um procedimento sistemático, reflexivo, controlado e crítico, que permite ao investigador encontrar novos conteúdos, situados em diferenciados campos científicos. Por sua vez, esta pesquisa se processa a partir do levantamento de bibliografia publicada em distintos formatos como: livros, revistas científicas, artigos inseridos em anais de congressos, websites, entre outros.

A reflexão proposta se justifica pela necessidade atual de discutir o papel das relações públicas a partir da relação entre a visibilidade e a busca da legitimação das organizações, distinguindo duas faces da comunicação. A comunicação não-midiática a qual se dá no mesmo tempo e espaço em que acontecem os fatos, ou seja, no lugar em que se realizam as práticas, e a comunicação midiática que se realiza através da mediação por tecnologias de comunicação e informação, por meio dos processos sociotécnicos, a qual se destaca na contemporaneidade.

Este artigo está estruturado em três sessões. Primeiramente, são apresentados o conceito de legitimação do contexto das organizações segundo os postulados de Peter Berger e Thomas Luckmann (1985). Em um segundo momento, são levantados os conceito de relações públicas a atuação dos profissionais de Relações Públicas, a partir de Simões (1987), Kunsch (2003) e Fortes (2003). Logo após, contextualiza-se a prática das relações públicas, destacando sua função política, na busca pela visibilidade 
midiática e pela legitimação das organizações assessoradas, a partir do que consideram os pesquisadores Simões (1987), Moura (2005), Kunsch (2003) e Kegler e Fossá (2007). O último tópico apresenta o papel das relações públicas e do profissional de RP no contexto da legitimação em um cenário que compreende a midiatização tanto dos processos sociais quanto da própria sociedade. Por fim, são apresentadas as considerações finais, retomando as principais questões levantadas neste artigo.

\section{Legitimação organizacional}

Conforme os sociólogos Peter Berger e Thomas Luckmann (1985), a noção de legitimação se refere à necessidade de explicar e justificar as práticas dos atores sociais individuais ou coletivos, esclarecendo o porquê de determinados fatos terem certa origem - 'serem o que são e como são', diante das sociedades. A legitimação pode ser registrada como um processo que concede validade e valor aos significados dos campos. Somente através dessa validação é possível transmitir as práticas e discursos dos campos sociais para as próximas gerações.

O conceito de legitimação possui uma relação estreita com os conceitos de institucionalização e de objetivação. A institucionalização, segundo os sociólogos Berger e Luckmann (1997), ocorre quando há uma tipificação recíproca de ações habituais por certos atores sociais, sendo que essas tipificações são acessíveis e partilhadas entre todos os membros do grupo social.

Em síntese, os indivíduos percebem os significados e se relacionam com os outros por intermédio de esquemas tipificados ou papéis sociais, os quais servem como códigos que regulam a maneira de pensar, agir e de comportar-se socialmente. Os atores sociais tendem a agir de acordo com certos padrões preestabelecidos socialmente e por eles incorporados em sua socialização primária.

A institucionalização ocorre quando acontece uma tipificação recíproca de papéis e ações rotineiras por atores sociais. Ações tornadas rotineiras referem-se a comportamentos que foram adotados por um ator ou grupo de atores a fim de resolver problemas recorrentes. Tais comportamentos são tornados habituais ou rotineiros à medida que são utilizados na tomada de decisões. Tipificação envolve o desenvolvimento recíproco de definições compartilhadas ou significados que estão ligados a estes comportamentos habituais. Uma vez que estas tipificações resultam em categorizações ou classificações que com a ação habitual se torna generalizada, isto é independente dos indivíduos específicos que desempenham a ação, esse processo de 
generalização do significado de uma ação é entendida como objetivação e é um dos componentes chaves do processo de institucionalização. Um outro elemento da institucionalização é a exterioridade que diz respeito ao grau em que as tipificações são vivenciadas como possuindo uma realidade própria. A exterioridade está relacionada à continuidade histórica das tipificações (ZUCKER, 1987) e à transmissão das tipificações aos novos membros que, não tendo conhecimento das suas origens, estão aptos a tratá-las como "dados sociais” (BERGER E LUCKMANN, 1997).

Desse modo, institucionalizar uma organização é torná-la aceita naturalmente para os membros desse grupo social, inspirando suas ações e práticas sociais. Institucionalizar processos comunicativos no interior das organizações, por exemplo, é torná-los habituais e rotineiros gerando efeitos práticos importantes como interação, informação, socialização secundária, representação social, produção do imaginário, etc. A institucionalização é um processo pelo qual atores individuais transmitem o que é socialmente definido como real (ZUCKER, 1987). Em outras palavras trata-se de um processo de fabricação de "verdades", desempenhado por diversos atores sociais, entre eles os Relações Públicas que graças a sua competência comunicativa estabelece relacionamentos produtivos entre a organização e públicos de interesse.

Para ser institucional, a estrutura deve gerar uma ação ou efeitos práticos. Segundo argumento de Giddens (1979), uma estrutura que não se traduz em ação é, uma estrutura não-social. Uma estrutura que se tornou institucionalizada é a que é considerada, pelos membros de um grupo social, como eficaz e necessária; ela serve, pois, como uma importante força causal de padrões estáveis de comportamentos (BERGER E LUCKMANN, 1997).

Inspirados em Simon (1957) podemos afirmar que em uma mesma organização existe o confronto entre várias "verdades" decorrentes das diferentes formas de percepção dos diversos grupos organizacionais e das diversas racionalidades existentes. Assim, certos grupos conseguem impor a outros grupos soluções baseadas em sua visão de mundo e em sua interpretação da realidade. Estas soluções são instituídas na organização por meio de regras, rotinas de trabalho, normas, estruturas organizacionais como sendo a "verdade" e a solução correta a ser tomada. Essa dinâmica ocorre também no nível de ambiente, ou seja, diversas organizações buscam influenciarem-se, estabelecendo quais modelos, práticas, símbolos serão institucionalizados, tornando-se habituais e rotineiros e influenciando a ação dos outros (ZUCKER, 1987). 
As organizações como atores sociais que interagem e moldam o ambiente são detentoras de um conjunto de regras e normas que as conformam para sobreviverem e obterem a legitimidade de outras organizações, agentes econômicos, governamentais e privados (MEYER e SCOTT, 1981). Em relação a criação e institucionalização de modelos gerenciais em um dado setor, Scott (1987) salienta que as organizações não adotam modelos e formas de representação que estão "na moda" por acreditarem que eles são os melhores, mas por serem "fonte de legitimidade, reconhecimento e recursos, permitindo aos atores sociais e organizacionais aumentar a sua capacidade de sobrevivência em um certo meio" (SCOTT, 1987, p. 79).

Reforçando o argumento de Scott, Motta e Vasconcellos salientam que uma organização que não incorpora,

[...] pelo menos superficialmente, de forma cerimonial, certas ferramentas de administração, certos jargões, símbolos e modos de funcionamentos considerados pelos formadores de opinião como os melhores em um dado momento será considerada ultrapassada e poderá perder clientes (2004, p. 399).

Ainda é Motta e Vasconcellos que ressaltam que pelo argumento apresentado por Scott (1987) de que as organizações adotam modelos e formas de representação para se legitimarem no campo e sobreviverem, o processo de institucionalização vai além da dimensão cognitivista de Berger e Luckmann (1997) para se estabelecer na dimensão estratégica. Pela visão cognitiva, o ser humano formula estratégias conforme percepções, padrões culturais e interpretações compartilhadas da realidade. Já pela abordagem institucionalista o homem é um ator social que formula suas estratégias "conforme os significados atribuídos às regras de funcionamento organizacional, institucionalizadas na sociedade" (MOTTA E VASCONCELLOS, 2004, p. 395).

Pode-se inferir, portanto, que quanto mais os campos sociais estão aptos de anunciar suas práticas, regras, valores, objetivos e estratégia fundamental, mais projetam sua legitimidade. De forma simultânea, quando mais legítimo for o campo social, mais claras, evidentes e distintas serão suas práticas, regras, valores e os objetivos para o sistema social e para as futuras gerações. A legitimação permite o agenciamento de sentidos aos campos sociais para que eles estejam aptos a negociar sua inserção no tecido social, garantindo, desse modo, sua sobrevivência.

É possível observar dois focos de legitimidade que um campo social pode possuir: a legitimidade vicária - originada da própria essência do campo e a 
legitimidade delegada por outro campo social. Como uma esfera específica de legitimidade, cada campo social, através de arranjos singulares que perpassam pela sua linguagem, está apto para se auto-representar, esclarecer, explicar e justificar suas práticas, buscando legitimá-las, no espaço privilegiado que compreende sua topografia.

A legitimação é construída através da linguagem, que representa o principal componente das experiências coletivas. Todavia, para possuir legitimação perante todo o tecido social, os campos sociais estão constantemente procurando espaços fora de sua área de atuação que lhes proporcionem significado, reconhecimento e respeito, reforçando seus objetivos e estratégia fundamental - sua existência propriamente dita. A conjuntura de legitimação de um campo social acaba por revelar o seu status em determinada sociedade.

\section{O pensamento estratégico no fazer e ser das relações públicas}

O pesquisador Roberto Porto Simões (1987), ao estudar as relações públicas no contexto das organizações, as observa primeiramente como um processo, ou seja, "Relações Públicas referem-se a um processo pluridimensional de interações das organizações com seus públicos" (SIMÕES, 1987, p.30). Esse processo é considerado amplo, leva em consideração fatores internos e externos à organização, causas e efeitos e todas as variáveis e tipos de relações, iniciadas tanto pela organização, quanto pelos públicos dessa organização.

As Relações Públicas são apresentadas como uma atividade específica no sistema organizacional, "com a finalidade de prever e controlar a função de relacionamento implícita ao agir organizacional” Simões (1987, p.31). As organizações investem em grandes campanhas de marketing e deixam em segundo plano a busca de bons relacionamentos. Relacionamentos esses, que necessitam ser justificados e explicados para que proporcionem o crescimento saudável dos negócios e a construção de uma imagem organizacional positiva. Para que se operacionalize, com eficiência, o estabelecimento de relacionamentos é necessário espaço físico, materiais, capitais e especialmente recursos humanos qualificados. Ao profissional preparado a desenvolver as atividades de relações públicas dá-se o nome de Relações Públicas.

O campo de ações de relações públicas no contexto das organizações é a comunicação organizacional. De modo geral, essa comunicação compreende todo o espectro de atividades e processos comunicacionais que se realizam no âmbito da organização. Para Kunsch (2003) a comunicação organizacional abarca - a comunicação 
administrativa - que se processa na ordem das ações administrativas e permite viabilizar a sistemática funcional da organização, a comunicação mercadológica - voltada ao marketing de negócios, a comunicação institucional - responsável pela construção da identidade e imagem corporativa de uma organização e a comunicação interna - que busca o estabelecimento do diálogo de forma a beneficiar tanto a organização quanto seus colaboradores. A organização que realiza sua comunicação em sintonia com essas modalidades realiza a comunicação integrada.

$\mathrm{Na}$ comunicação organizacional as relações públicas atuam no sentido de organizar as políticas de comunicação, interação e relacionamento com os seus públicos específicos. Os arranjos resultantes de relações públicas bem sucedidas no contexto das organizações são capazes de promover uma comunicação organizacional mais fluida, dinâmica e equilibrada.

Para o pesquisador Waldyr Gutierrez Fortes (2003, p.21), “às Relações Públicas está reservado o trabalho de conhecer e analisar os componentes do cenário estratégico de atuação das empresas, com a finalidade de conciliar os diversos interesses." Nesse sentido, como objetivos principais das práticas de relações públicas destaca-se: a busca pelo reconhecimento das organizações, seus produtos e serviços, pelos seus públicos e a promoção da comunicação, interação e relacionamento públicoorganização de modo equilibrado e, por vezes, duradouro e, com isso, impulsionar o desenvolvimento organizacional.

No exercício das atividades de relações públicas, o profissional conta com diferentes ferramentas tais como - a pesquisa, o diagnóstico, os planos, programas e projetos, as técnicas de avaliação, a comunicação de massa e a comunicação dirigida. Conforme Kunsch (2003), podemos destacar quatro funções essenciais do profissional, a saber: função administrativa, função estratégica, função mediadora e função política (teoria de conflitos-resoluções). Ainda segundo a mesma autora, a função política caracteriza-se como o "desenvolvimento de atividades ligadas basicamente às relações de poder dentro das instituições e com a administração de controvérsia, confrontações, crises e conflitos sociais, que acontecem no ambiente do qual a instituição faz parte". A partir desta função, podemos inferir que é do Relações Públicas a responsabilidade pelo gerenciamento das ações e estratégias organizacionais na qual seus impactos precisam ser entendidos e aceitos como úteis e compatíveis pela sociedade. O equilíbrio das opiniões entre organização e seus públicos é um indício da construção dessa legitimação (SIMÕES 1987). 
A probabilidade iminente de que ocorram conflitos nas relações organizacionais, tanto no lado da organização como no âmbito dos públicos destaca a necessidade da função política para que monitore alguma desordem em potencial e as alinhem para uma direção harmônica. Na contemporaneidade, se analisarmos as fusões corporativas temos um nítido exemplo de como uma mudança (algumas vezes conduzida cautelosamente e outras nem tanto) pode provocar uma série de conflitos e informações incompletas e ambíguas. Insegurança, incertezas, pressuposições e necessidade de adaptação são alguns aspectos que demandam a prática dessa função de Relações Públicas e um gerenciamento estratégico como forma de controle da situação.

Essas funções são essenciais para a gestão da comunicação organizacional e são a base para um dos principais instrumentos de trabalho de RP que é o planejamento. Esse planejamento pode ser composto apenas por ações que envolvem as relações públicas de uma organização ou contemplar toda a comunicação organizacional. Kunsch (2003, p.216) vê o planejamento como uma atividade que evita que ações sejam executadas ao acaso, sem qualquer preocupação com a eficiência, a eficácia e a efetividade para o alcance de resultados.

Considera-se uma das características do profissional de Relações Públicas o “pensamento estratégico". No mesmo sentido de buscar a eficiência, cada atividade das Relações Públicas, inclui-se aqui todo o processo de concepção do planejamento de relações públicas ou de comunicação, tem de estar permeada por um pensar estrategicamente. Para Kunsch (2003), o "pensamento estratégico" compreende uma atitude intuitiva e criativa e uma visão sistêmica, dinâmica e aberta.

O pensamento estratégico não se prende à rigidez dos quadros e diagramas e busca descobrir novas e várias alternativas, isto é, não se prende a dar uma única resposta ou a resposta certa, mas levanta questões e equaciona o estabelecido formalmente. (KUNSCH, 2003, p. 241)

Além desses fatores que remetem à sensibilidade, o "pensamento estratégico" "requer o conhecimento da organização e de suas condições, aspirações e aportes técnicos e tecnológicos" (KUNSCH, 2003, p. 241). Portanto, somente através desse movimento estratégico, guiado pelo raciocínio crítico, perspicaz, criativo e flexível é possível antecipar eventualidades no processo de relações públicas e potencializar acertos.

Vale ressaltar que as relações públicas estão, também, associadas à questão dos públicos. Fortes (2003) vê que o trabalho do profissional de Relações Públicas está 
focado na investigação pormenorizada de seus públicos. De modo estratégico, ele desenvolve artifícios de pesquisa para identificar nos indivíduos e grupos organizados, comportamentos e formas de contato, que venham facilitar o estabelecimento do processo de comunicação, interação e relacionamento com as organizações. Portanto constata-se que compete as Relações Públicas administrar estrategicamente a comunicação da organização com seus públicos, atuando em sinergia com as demais modalidades comunicacionais.

Evidencia-se, no entanto, que o "pensamento estratégico" na atividade de Relações Públicas está imbricado por entraves internos e externos. Os entraves internos se apresentam quando o profissional ainda não se vê como definidor das representações e da realidade de seus assessorados. Os entraves externos são verificados quando as próprias organizações assessoradas limitam a sua atuação, muitas vezes, por desconhecer seus intuitos verdadeiros e suas habilidades. Nesse sentido, observam-se as colocações de Kegler (2008) que, no contexto da "sociedade midiatizada", vê o "pensar" e "agir" estrategicamente das Relações Públicas a partir do devir - do "vir a ser".

Esse "vir a ser" é caracterizado eminentemente pela influência do espaço midiatizado da atualidade, onde as ações precisam ser estratégicas para: o estabelecimento da relação de comunicação entre instituições e públicos; possibilitar através da relação de comunicação o diálogo entre as partes e o debate de interesse público; a legitimação institucional por ações dialógicas de reconhecimento, não por ações persuasivas; e quem sabe, a contribuição para cidadania e democracia no país (KEGLER, 2008, p.70).

Independente do contexto em que se esteja sendo desenvolvida, toda a atividade de relações públicas tem de estar alinhada estritamente aos objetivos das organizações assessoradas. E, de acordo com Fortes implantar um processo de Relações Públicas é "posicionar uma organização em direção de seus objetivos maiores, de maneira coerente e sistematicamente racional, à procura de resultados concretos estabelecidos com antecedência" (FORTES 2003, p. 23). Desde suas funções básicas, as Relações Públicas já apresentam seu caráter estratégico, uma vez que darão suporte aos relacionamentos estabelecidos a fim de representar a organização perante seus públicos e ambientes.

\section{O papel das relações públicas na legitimação organizacional}

O Relações Públicas, através da sua visão global de administrador da comunicação, tem a competência para estruturar a comunicação midiática 
organizacional utilizando estratégias que potencializem a divulgação de informações e assegurar a presença da organização no espaço público. Por isso, um dos principais objetivos da profissão caracteriza-se na busca da legitimação da organização assessorada.

Toda organização, de forma planejada ou não, busca sua permanência no mercado e, consequentemente, sua legitimação na sociedade em que está inserida. Dentro do atual contexto marcado pela rápida transformação e evolução das tecnologias da comunicação e da informação, a globalização, a mudança nas naturezas de trabalho, os problemas ecológicos e os mercados turbulentos essa necessidade de legitimar-se torna-se cada vez mais relevante e, algumas vezes, pode significar sua permanência ou não no mercado.

Como comentamos anteriormente, a função política bem desenvolvida, já representa um primeiro passo à legitimação organizacional. É preciso estabelecer uma relação equilibrada entre organização e seus públicos, de forma a harmonizar os objetivos e interesses dos atores envolvidos. Os processos de fusão/aquisição corporativa tipificam-se como exemplos da necessidade de se colocar em prática essa negociação de interesses, de estabelecer um fluxo contínuo de comunicação com a mídia e, consequentemente com a sociedade, além de auto-gerenciar sua visibilidade. $\mathrm{O}$ avanço das tecnologias apresentam novas possibilidades e ferramentas de comunicação estratégicas e de grande amplitude, como por exemplo os sites organizacionais. A utilização adequada desses espaços possibilita um planejamento da visibilidade midiática organizacional, sem necessariamente passar pelos medias. A fusão mais recentemente acompanhada foi dos Bancos Itaú e Unibanco, onde podemos observar a utilização da prática de auto-gerenciamento da visibilidade, uma vez que o site organizacional do Itaú (como hoje as duas empresas formam uma única, a seção "assessoria de impresa" está presente no site do Itaú em www.itau.com.br) disponibiliza informações a respeito do processo, desde vídeos da coletiva de imprensa até releases enviados e clipping. São estratégias de visibilidade que objetivam a explicação e justificativa do porquê de tal decisão buscando a legitimação social.

No desenrolar de suas atividades os profissionais da área buscam criar diferenciadas estratégias para que as práticas organizacionais se tornem legítimas diante de determinado meio social. Devido à sua visão, tanto dos ambientes como dos acontecimentos, o Relações Públicas está apto a planejar e executar estrategicamente processos de comunicação que visam à legitimidade organizacional. 
A atividade de Relações Públicas ao utilizar estrategicamente os recursos e meios disponíveis integrados às suas ações de comunicação se configura como gerenciadora da visibilidade das organizações com habilidade para divulgar e gerar fatos (eventos, premiações, lançamento de produtos, informativo interno) e, conforme Kegler "apresentar a institutuição com suas próprias palavras (através de planejamento do site institucional, dos murais, das malas-diretas e do material de divulgação) sem estar sujeita de imediato às condições de produção dos veículos tradicionais da mídia" (2008, p. 33).

Devido à complexidade da sociedade atual, esse processo de legitimação, iniciado no ambiente interno das organizações, ainda não está completo, pois também é preciso justificar-se perante a sociedade. Essa necessidade da organização legitimar-se nos demais ambientes passará, obrigatoriamente, pelos meios de comunicação, ou seja, será através das mídias que suas práticas se tornarão visíveis à toda sociedade. Em outras palavras podemos dizer que na contemporaneidade a cena da legitimação, vem sendo transferida do local onde ocorrem as práticas organizacionais para o campo dos mídias.

Através dos espaços midiáticos são operadas as estratégias midiáticas, as quais unem elementos sociais e técnicos - sociotécnicos. Sociais principalmente porque se processam a partir de relações entre atores sociais e porque apresentam especificidades contextuais e ideológicas. Técnicas porque dependem, de maneira exclusiva, de recursos tecnológicos e de certas técnicas para a sua operacionalização. A conjunção desses dois elementos, que são complexos, remete significados e propõe efeitos de sentidos específicos aos conteúdos circulantes nesses espaços.

Afirma-se, portanto, que é através das mídias que os campos terão a oportunidade de posicionarem-se no espaço público. Nessa estrutura social está presente a lógica das mídias, já que argumentos, decisões e ações serão determinadas através de mediações sociais simbólicas, pelos meios, sejam ou não tecnológicos.

Em suas pesquisas sobre os movimentos de mobilização social, Mafra (2006) relata que os recursos dos espaços midiáticos são fundamentais no sentido de promover o reconhecimento de determinados temas. "Através da mídia, projetos de mobilização podem não só ganhar visibilidade pública como também expandir a constituição de um novo público em formação" (MAFRA, 2006, p. 40).

As organizações passam a definir as formas de se fazerem reconhecer, segundo lógica, cultura e operações de natureza midiática, ora na formulação de estratégias de 
negócio e de gestão, ora na busca de visibilidade e de validação pública de sua atuação. Assim, a elaboração de estratégias midiáticas permite às organizações transitarem na esfera da visibilidade midiática e serem reconhecidas também como sujeitos políticos.

Ao estudar a comunicação das universidades, em um quadro em que instituições universitárias públicas acabaram perdendo certa legitimidade devido aos novos padrões de legitimidade impostos pela racionalidade de mercado ao campo da educação, a pesquisadora Eugenia Mariano da Rocha Barichello (2002) observa a importância da visibilidade ${ }^{\text {iv }}$ midiática nessa conjuntura. A autora considera que "os mídia são o principal dispositivo contemporâneo de visibilidade da instituição universitária, sendo responsáveis em grande parte pela legitimação junto à sociedade" (BARICHELLO, 2001, p. 78). Dessa forma, ao tornarem determinadas práticas e questões visíveis nos meios de comunicação os campos sociais se preparam para pleitear certa legitimidade social. Para Barichello,

[...] é possível observar uma transferência da cena do processo de legitimação, que deixa de ser o local onde ocorrem as práticas institucionais e inclui, cada vez mais, a representação e justificação das mesmas nos meios de comunicação de massa. (2002, p.36).

No ambiente em que a mídia é um importante dispositivo contemporâneo de visibilidade da instituição, prosperam aqueles que possuem mais informações e habilidades para propor soluções e respostas aos acontecimentos. É exatamente por este motivo que a atividade de relações públicas tem seu princípio bem anterior a apenas o envio de releases, uma vez que à medida que as ações de comunicação se posicionam estrategicamente o fato de realizar um diagnóstico já se configura como uma valiosa fonte de informações. Para Kegler,

As Relações Públicas podem ocupar lugar de sujeito estratégico nas organizações, pois além de prever e planejar podem apresentar uma visão global da instituição e do ambiente. Tal habilidade proporciona respostas rápidas com base nas informações já existentes, ou se não existentes, com base em fontes que já são conhecidas, facilitando o contato e a formulação de ações estratégicas. (2008, p. 37)

A partir dessa visão estratégica o Relações Públicas, principalmente no que se refere aos relacionamentos entre organizações e seus públicos, precisa planejar e executar estratégias midiáticas. Portanto, buscar sua legitimação, através de espaços midiáticos, pode ser considerado hoje como uma das mais relevantes estratégias abraçadas pelas organizações. Mas também, faz-se necessário ressaltar que, embora se 
remeta relevância à legitimação possibilitada pelos diferentes espaços midiáticos, não significa que a existência fora deles seja desprezada. Apenas, entendemos que quem não tem passagem pelos espaços midiáticos encontra-se aquém do amplo e diversificado ambiente de possibilidade de reconhecimento e de comunicação.

\section{Considerações finais}

Através dos processos de legitimação as organizações são reconhecidas e significadas fazendo sentido para os seus públicos, o que colabora para a permanência no tempo e a construção identitária constante diante das disputas simbólicas travadas entre os diversos campos sociais ou dentro de um mesmo campo. Em outras palavras, a permanência de uma organização vai depender do seu reconhecimento e da legitimação de suas ações na sociedade em que está inserida. São várias as estratégias utilizadas pelas organizações para a busca de sua legitimação como: eventos empresariais, cerminoniais, cursos, palestras, apresentações artísticas, workshops. Todas configuramse como práticas de Relações Públicas que legitimam a organização perante seus públicos específicos.

Atualmente as tecnologias complexificaram as formas de comunicação e consequentemente as estratégias de legitimação. Em um ambiente de disputas e significações para legitimar-se perante os públicos é cada vez mais necessária a utilização de estratégias midiáticas. Uma vez que, na contemporaneidade a mídia pode ser vista como uma esfera de visibilidade, exercendo um importante papel no que se refere à legitimação das instituições.

A visibilidade pelo campo midiático se torna essencial quando as organizações conscientizam-se dos desafios que necessitam transpor diariamente, frutos de um contexto de incertezas e instabilidade. Esse processo depende cada vez mais dos agenciamentos com os meios de comunicação, uma vez que estes atuarão como o local que torna visíveis as ações e, logo, capazes de contribuir na sua legitimidade.

Por fim, verifica-se que anteriormente o processo de legitimação tendia a dar-se exclusivamente no espaço da própria instituição ou, pelo menos, em situações de interação face a face, hoje pelo processo de midiatização as organizações são instigadas a estarem na mídia e a serem fontes de informações para os mais variados campos da sociedade.

A comunicação, independente do ambiente em que se desenvolva (midiático ou não-midiático), é responsável pela legitimação organizacional e por isso o Relações 
Públicas, com suas práticas, funções e ferramentas, apresenta-se como um profissional preparado para trabalhar estrategicamente esta busca. Sabe-se que as decisões organizacionais se dão a partir de um processo decisório, envolvendo óticas e interesses variados. Desta forma, através de sua função política o profissional atuará buscando a harmonização dos relacionamentos e propiciando um contexto adequado e favorável em busca da visibilidade das ações organizacionais, justificando e explicando as práticas da mesma.

$\mathrm{Na}$ atualidade, os públicos deixaram sua característica de passividade e assumiram uma postura mais ativa perante as informações recebidas tanto do contexto organizacional quanto do espaço midiático. Portanto, através do diálogo, de uma comunicação que estimule a troca, o intercâmbio e a interação, e de estratégias de relacionamento com seus públicos o Relações Públicas busca conquistar a legitimação organizacional.

\section{Referências}

BARICHELLO, Eugenia. Comunicação e comunidade do saber. 1. ed. Santa Maria: Pallotti, 2001.

Eugenia Mariano

A construção da visibilidade institucional pela mídia. In: da Rocha Barichello; Ada Cristina Machado Silveira; Adair Caetano Peruzzolo; Veneza Maiora Ronsini. (Org.). Comunicação Midiática. Santa Maria: FACOS/UFSM, 2002, v. 1, p. 33-58.

BERGER, Peter \& LUCKMANN, Thomas. A construção social da realidade. Petrópolis: $6^{\mathrm{a}}$ ed. Vozes, 1985.

FORTES, Waldir Gutierrez. Relações Públicas - processo, funções, tecnologia e estratégias. São Paulo: 2. Ed. Summus, 2003.

GIDDENS, Anthony. Central Problems in Social Theory: Action, Structure and Contradiction in social Analysis. Berkeley, Califórnia: University of California Press, 1979.

KEGLER, Jaqueline Quincozes S.; FOSSÁ, Maria Ivete Trevisan. Relações Públicas e Midiatização. In: CONGRESSO DE CIÊNCIAS DA COMUNICAÇÃO NA REGIÃO SUL, 17, 2007, Passo Fundo. Anais eletrônicos. CD-ROM.

Comunicação pública e complexidade: uma perspectiva das Relações Públicas como sujeito comunicacional e estratégico no cenário da midiatização. Dissertação Mestrado em Comunicação. Universidade Federal de Santa Maria (UFSM), Santa Maria, 2008.

KUNSCH, Margarida Maria Krohling. Planejamento de relações públicas na comunicação integrada. São Paulo: Summus, 2003.

MARCONI, Marina de Andrade; LAKATOS, Eva Maria. Fundamentos de metodologia científica. São Paulo: Atlas, 2006.

MAFRA, Rennan. Entre o espetáculo, a festa e a argumentação: mídia, comunicação estratégica e mobilização social. Belo Horizonte: Autêntica, 2006. 
MOTTA, Fernando C. Prestes; VASCONCELOS, Isabella F. Gouveia de. Teoria Geral da Administração. São Paulo: Pioneira Thomson Learning, 2004.

MOURA, Cláudia Peixoto de. A prática da pesquisa empírica em um portal cooperativo. UNIrevista, São Leopoldo: Editora Unisinos, v. 1, n. 3, p. 1-12, jul. 2006. Disponível em: <http://www.unirevista.unisinos.br/_pdf/UNIrev_Peixoto.PDF> Acesso em: 25 de jun 2008.

RODRIGUES, Adriano Duarte. Estratégias da Comunicação. Questão comunicacional e formas de sociabilidade. Lisboa: Presença, 1997.

SGORLA, Fabiane. Estratégias Midiáticas em Sites de Organizações Privadas: A Busca Pela Visibilidade da Responsabilidade Social Organizacional. Dissertação Mestrado em Comunicação. Universidade Federal de Santa Maria (UFSM), Santa Maria, 2009.

SIMÕES, Roberto Porto. Relações Públicas: Função Política. Novo Hamburgo: Feevale, 1987.

SIMON, H. Models of Man. New York: John Wiley, 1957.

SCOTT, W. R. The adolescence of institutional theory. Administrative Science

Quartely, 1987, vol. 32, p. 493-511

SCOTT, W. R. MEYER, J. W. The organization of societal sectors. Propositions and early evidence. In: DIMAGGIO P.; POWELL, E. (Ed.) The new institutionalism in organizational analysis. Chicago: The University of Chicago Press, 1991, p.83-107. ZUCKER, L. G. Institutional theories of organizations. Annual Review of Sociology, 1987, vol. 13, p.443-464.

\section{Notas}

\footnotetext{
i Mestre em Comunicação Midiática/UFSM, Especialista em Comunicação Midiática/UFSM fabisgorla@hotmail.com.

ii Mestranda em Comunicação Midiática/UFSM e integrante do Grupo de Pesquisa Comunicação Institucional e Organizacional UFSM/CNPq. patriciapersigo@gmail.com

iii Professora do Programa de Pós Graduação em Comunicação da UFSM e do Programa de PósGraduação em Administração da UFSM. Doutora em Administração pela UFRGS e Mestre em Comunicação pela UMESP. fossa@terra.com.br
} 